\title{
Some Fixed Point Results for Generalized Weak Contraction Mappings in Modular Spaces
}

\author{
Chirasak Mongkolkeha and Poom Kumam \\ Department of Mathematics, Faculty of Science, King Mongkut's University of Technology Thonburi, Bang Mod, Thung Khru, \\ Bangkok 10140, Thailand
}

Correspondence should be addressed to Poom Kumam; poom.kum@kmutt.ac.th

Received 18 August 2012; Revised 9 February 2013; Accepted 19 February 2013

Academic Editor: Stefan Kunis

Copyright (c) 2013 C. Mongkolkeha and P. Kumam. This is an open access article distributed under the Creative Commons Attribution License, which permits unrestricted use, distribution, and reproduction in any medium, provided the original work is properly cited.

We prove the existence theorem of fixed points for a generalized weak contractive mapping in modular spaces.

\section{Introduction}

In 1997, Alber and Guerre-Delabriere [1] introduced the concept of weak contraction in Hilbert spaces. Later, Rhoades [2] proved that the result which Alber et al. is also valid in complete metric spaces, the result of Rhoades in the following: A mapping $T: X \rightarrow X$ where $(X, d)$ is a metric space, is said to be weakly contractive if

$$
d(T(x), T(y)) \leq d(x, y)-\phi(d(x, y)),
$$

where $\phi:[0, \infty) \rightarrow[0, \infty)$ is continuous and nondecreasing function such that $\phi(t)=0$ if and only if $t=0$. In 2008, Dutta and Choudhury [3] introduced a new generalization of contraction in metric spaces and proved the following theorem.

Theorem 1. Let $(X, d)$ be a complete metric space, and let $T$ : $X \rightarrow X$ be a self-mapping satisfying the following inequality:

$$
\psi(d(T x, T y)) \leq \psi(d(x, y))-\phi(d(x, y)),
$$

where $\psi, \phi:[0, \infty) \rightarrow[0, \infty)$ are both continuous and monotone nondecreasing function with $\psi(t)=\phi(t)=0$ if and only if $t=0$. Then $T$ has a unique fixed point.

We note that, if one takes $\psi(t)=t$, then (2) reduces to (1).
Recall that the theory of modular on linear spaces and the corresponding theory of modular linear spaces were founded by Nakano $[4,5]$ and redefined by Musielak and Orlicz [6]. Furthermore, the most complete development of these theories is due to Mazur, Luxemburg, and Turpin [79]. In the present time, the theory of modular and modular spaces is extensively applied, in particular, in the study of various Orlicz spaces which in their turn have broad applications [10-14]. In many cases, particularly in applications to integral operators, approximation and fixed point theory, modular-type conditions are much more natural as modulartype assumptions can be more easily verified than their metric or norm counterparts. Even though a metric is not defined, many problems in metric fixed point theory can be reformulated in modular spaces. For instance, fixed point theorems are proved in $[15,16]$ for nonexpansive mappings. The existences for contraction mapping in modular spaces has been studied in [3, 17-24] and the references therein.

From the above mentioned, we will study the existence of fixed point theorems for mappings satisfying generalized weak contraction mappings in modular spaces.

\section{Preliminaries}

First, we start with a brief recollection of basic concepts and facts in modular spaces. 
Definition 2. Let $X$ be a vector space over $\mathbb{R}$ (or $\mathbb{C}$ ). A functional $\rho: X \rightarrow[0, \infty]$ is called a modular if for arbitrary $x$ and $y$, elements of $X$, it satisfies the following conditions:

(1) $\rho(x)=0$ if and only if $x=0$;

(2) $\rho(\alpha x)=\rho(x)$ for all scalar $\alpha$ with $|\alpha|=1$;

(3) $\rho(\alpha x+\beta y) \leq \rho(x)+\rho(y)$, whenever $\alpha, \beta \geq 0$ and $\alpha+\beta=1$.

If one replaces (3) by

(4) $\rho(\alpha x+\beta y) \leq \alpha^{s} \rho(x)+\beta^{s} \rho(y)$, for $\alpha, \beta \geq 0, \alpha^{s}+\beta^{s}=1$ with an $s \in(0,1]$, then the modular $\rho$ is called $s$ convex modular, and if $s=1, \rho$ is called convex modular.

If $\rho$ is modular in $X$, then the set

$$
X_{\rho}=\{x \in X: \rho(\lambda x) \longrightarrow 0 \text { as } \lambda \longrightarrow 0\},
$$

is called a modular space. $X_{\rho}$ is a vector subspace of $X$.

Definition 3. A modular $\rho$ is said to satisfy the $\Delta_{2}$-condition if $\rho\left(2 x_{n}\right) \rightarrow 0$, whenever $\rho\left(x_{n}\right) \rightarrow 0$ as $n \rightarrow \infty$.

Definition 4. Let $X_{\rho}$ be a modular space.

(1) The sequence $\left\{x_{n}\right\}_{n \in \mathbb{N}}$ in $X_{\rho}$ is said to be $\rho$-convergent to $x \in X_{\rho}$ if $\rho\left(x_{n}-x\right) \rightarrow 0$, as $n \rightarrow \infty$.

(2) The sequence $\left\{x_{n}\right\}_{n \in \mathbb{N}}$ in $X_{\rho}$ is said to be $\rho$-Cauchy if $\rho\left(x_{n}-x_{m}\right) \rightarrow 0$, as $n, m \rightarrow \infty$.

(3) A subset $C$ of $X_{\rho}$ is said to be $\rho$-closed if the $\rho$-limit of a $\rho$-convergent sequence of $C$ always belong to $C$.

(4) A subset $C$ of $X_{\rho}$ is said to be $\rho$-complete if any $\rho$ Cauchy sequence in $C$ is $\rho$-convergent sequence and its $\rho$-limit is in $C$.

(5) A subset $C$ of $X_{\rho}$ is said to be $\rho$-bounded if any $\delta_{\rho}(C)=$ $\sup \{\rho(x-y) ; x, y \in C\}<\infty$.

Definition 5. Let $X$ be a nonempty set and $T: X \rightarrow X$. A point $x \in X$ is a fixed point of $T$ if and only if $T x=x$.

Definition 6. Let $C$ be a subset of a real numbers $\mathbb{R}$. A mapping $T: C \rightarrow \mathbb{R}$ is called monotone increasing (or monotone nondecreasing) $x \leq y$ if and only if $T(x) \leq T(y)$, for all $x$ and $y$ are elements in $C$. A mapping $T: C \rightarrow \mathbb{R}$ is called monotone decreasing (or monotone nonincreasing), $x \geq y$ if and only if $T(x) \geq T(y)$ for all $x$ and $y$ are elements in $C$.

Definition 7. A sequence $\left\{a_{n}\right\}$ of a real number is said to be monotone increasing (or monotone nondecreasing), if it satisfies $a_{1} \leq a_{2} \leq a_{3} \leq \ldots$. It is also said to be monotone decreasing (or monotone nonincreasing) if it satisfies $a_{1} \geq$ $a_{2} \geq a_{3} \geq \ldots$

\section{A Generalized Weak Contraction in Modular Spaces}

In this section, we prove fixed point theorems for mappings satisfying generalized weak contractions in modular spaces.
Proposition 8. Let $\rho$ be a modular space on $X$. If $a, b \in \mathbb{R}^{+}$ with $b \geq a$, then $\rho(a x) \leq \rho(b x)$.

Proof. In case $a=b$, we are done. Suppose $b>a$, and then one has $a / b<1$ and

$$
\begin{aligned}
\rho(a x) & =\rho\left(\frac{a}{b} b x\right) \\
& =\rho\left(\frac{a}{b} b x+\left(1-\frac{a}{b}\right)(0)\right) \\
& \leq \rho(b x)+\rho(0) \\
& =\rho(b x) .
\end{aligned}
$$

Proposition 9. Let $X_{\rho}$ be a modular space in which $\rho$ satisfies the $\Delta_{2}$-condition and let $\left\{x_{n}\right\}_{n \in \mathbb{N}}$ be a sequence in $X_{\rho}$. If $\rho\left(c\left(x_{n}-x_{n-1}\right)\right) \rightarrow 0$ as $n \rightarrow \infty$, then $\rho\left(\alpha l\left(x_{n}-x_{n-1}\right)\right) \rightarrow 0$ as $n \rightarrow \infty$, where $c, l, \alpha \in \mathbb{R}^{+}$with $c>l$ and $l / c+1 / \alpha=1$.

Proof. Since $\rho\left(c\left(x_{n}-x_{n-1}\right)\right) \rightarrow 0$ as $n \rightarrow \infty$, by the $\Delta_{2^{-}}$ condition, we get

$$
\rho\left(2^{m} c\left(x_{n}-x_{n-1}\right)\right) \longrightarrow 0 \quad \text { as } n \longrightarrow \infty
$$

for $m \in \mathbb{N}$. Using (5), Proposition 8, and the sandwich theorem, we conclude that

$$
\rho\left(2 N c\left(x_{n}-x_{n-1}\right)\right) \longrightarrow 0 \quad \text { as } n \longrightarrow \infty,
$$

for $N \in \mathbb{N}$. From the fact that $l / c+1 / \alpha=1$, we get $\alpha l=$ $(\alpha-1) c \geq c$, then there exist $N_{\alpha} \in \mathbb{N}$ such that

$$
2\left(N_{\alpha}-1\right) c \leq(\alpha-1) c \leq 2\left(N_{\alpha}\right) c
$$

By Proposition 8, we get

$$
\begin{aligned}
& \rho\left(2\left(N_{\alpha}-1\right) c\left(x_{n}-x_{n-1}\right)\right) \\
& \leq \rho\left((\alpha-1) c\left(x_{n}-x_{n-1}\right)\right) \\
& \leq \rho\left(2\left(N_{\alpha}\right) c\left(x_{n}-x_{n-1}\right)\right) .
\end{aligned}
$$

From (6) and (8), we obtain

$$
\begin{aligned}
& \lim _{n \rightarrow \infty} \rho\left(\alpha l\left(x_{n}-x_{n-1}\right)\right) \\
& \quad=\lim _{n \rightarrow \infty} \rho\left((\alpha-1) c\left(x_{n}-x_{n-1}\right)\right)=0 .
\end{aligned}
$$

Theorem 10. Let $X_{\rho}$ be a $\rho$-complete modular space, where $\rho$ satisfies the $\Delta_{2}$-condition. Let $c, l \in \mathbb{R}^{+}, c>l$, and $T: X_{\rho} \rightarrow$ $X_{\rho}$ be a mapping satisfying the inequality

$$
\begin{aligned}
& \psi(\rho(c(T x-T y))) \\
& \quad \leq \psi(\rho(l(x-y)))-\phi(\rho(l(x-y))),
\end{aligned}
$$

for all $x, y \in X_{\rho}$, where $\psi, \phi:[0, \infty) \rightarrow[0, \infty)$ are both continuous and monotone nondecreasing functions with $\psi(t)=$ $\phi(t)=0$ if and only if $t=0$. Then, $T$ has a unique fixed point. 
Proof. Let $x_{0} \in X_{\rho}$, and we construct the sequence $\left\{x_{n}\right\}_{n \in \mathbb{N}}$ by $x_{n}=T x_{n-1}, n=1,2,3, \ldots$. First, we prove that the sequence $\left\{\rho\left(c\left(T x_{n}-T x_{n-1}\right)\right)\right\}$ converges to 0 . Indeed

$$
\begin{aligned}
\psi\left(\rho\left(c\left(x_{n}-x_{n+1}\right)\right)\right) \leq & \psi\left(\rho\left(l\left(x_{n-1}-x_{n}\right)\right)\right) \\
& -\phi\left(\rho\left(l\left(x_{n-1}-x_{n}\right)\right)\right) \\
\leq & \psi\left(\rho\left(l\left(x_{n-1}-x_{n}\right)\right)\right) .
\end{aligned}
$$

By monotone nondecreasing of $\psi$ and Proposition 8 , we have

$$
\begin{aligned}
\rho\left(c\left(x_{n}-x_{n+1}\right)\right) & \leq \rho\left(l\left(x_{n-1}-x_{n}\right)\right) \\
& \leq \rho\left(c\left(x_{n-1}-x_{n}\right)\right) .
\end{aligned}
$$

This means that the sequence $\left\{\rho\left(c\left(x_{n}-x_{n-1}\right)\right)\right\}$ is monotone decreasing and bounded below. Hence there exists $r \geq 0$ such that

$$
\lim _{n \rightarrow \infty} \rho\left(c\left(x_{n}-x_{n-1}\right)\right)=r .
$$

If $r>0$, taking $n \rightarrow \infty$ in the inequality (11), we get

$$
\begin{aligned}
\psi(r) & \leq \psi(r)-\phi(r) \\
& <\psi(r),
\end{aligned}
$$

which is a contradiction, thus $r=0$. So we have

$$
\rho\left(c\left(x_{n}-x_{n-1}\right)\right) \longrightarrow 0 \text { as } n \longrightarrow \infty \text {. }
$$

Next, we prove that the sequence $\left\{c x_{n}\right\}_{n \in \mathbb{N}}$ is a $\rho$-Cauchy. Suppose that $\left\{c x_{n}\right\}_{n \in \mathbb{N}}$ is not $\rho$-Cauchy, then there exist $\varepsilon>0$ and subsequence $\left\{x_{m_{k}}\right\},\left\{x_{n_{k}}\right\}$ with $m_{k}>n_{k} \geq k$ such that

$$
\rho\left(c\left(x_{m_{k}}-x_{n_{k}}\right)\right) \geq \varepsilon, \quad \rho\left(c\left(x_{m_{k}-1}-x_{n_{k}}\right)\right)<\varepsilon .
$$

Now, let $\alpha \in \mathrm{R}^{+}$such that $l / c+1 / \alpha=1$, then we get

$$
\begin{aligned}
\psi\left(\rho\left(c\left(x_{m_{k}}-x_{n_{k}}\right)\right)\right) \leq & \psi\left(\rho\left(l\left(x_{m_{k}-1}-x_{n_{k}-1}\right)\right)\right) \\
& -\phi\left(\rho\left(l\left(x_{m_{k}-1}-x_{n_{k}-1}\right)\right)\right) \\
\leq & \psi\left(\rho\left(l\left(x_{m_{k}-1}-x_{n_{k}-1}\right)\right)\right)
\end{aligned}
$$

which implies that

$$
\rho\left(c\left(x_{m_{k}}-x_{n_{k}}\right)\right) \leq \rho\left(l\left(x_{m_{k}-1}-x_{n_{k}-1}\right)\right) .
$$

We have

$$
\begin{aligned}
\rho\left(l\left(x_{m_{k}-1}-x_{n_{k}-1}\right)\right)= & \rho\left(l\left(x_{m_{k}-1}-x_{n_{k}}+x_{n_{k}}-x_{n_{k}-1}\right)\right) \\
= & \rho\left(\frac{l}{c} c\left(x_{m_{k}-1}-x_{n_{k}}\right)\right. \\
\quad & \left.\quad+\frac{1}{\alpha} \alpha l\left(x_{n_{k}}-x_{n_{k}-1}\right)\right) \\
\leq & \rho\left(c\left(x_{m_{k}-1}-x_{n_{k}}\right)\right) \\
& +\rho\left(\alpha l\left(x_{n_{k}}-x_{n_{k}-1}\right)\right) \\
< & \varepsilon+\rho\left(\alpha l\left(x_{n_{k}}-x_{n_{k}-1}\right)\right) .
\end{aligned}
$$

By (16), (18), and (19), we get

$$
\begin{aligned}
\varepsilon & \leq \rho\left(c\left(x_{m_{k}}-x_{n_{k}}\right)\right) \\
& \leq \rho\left(l\left(x_{m_{k}-1}-x_{n_{k}-1}\right)\right) \\
& <\varepsilon+\rho\left(\alpha l\left(x_{n_{k}}-x_{n_{k}-1}\right)\right) .
\end{aligned}
$$

Using (15) and Proposition 9, we have

$$
\lim _{k \rightarrow \infty} \rho\left(\alpha l\left(x_{n_{k}}-x_{n_{k}-1}\right)\right)=0 .
$$

From (20) and (21), we obtain

$$
\begin{aligned}
& \lim _{k \rightarrow \infty} \rho\left(c\left(x_{m_{k}}-x_{n_{k}}\right)\right) \\
& \quad=\lim _{k \rightarrow \infty} \rho\left(l\left(x_{m_{k}-1}-x_{n_{k}-1}\right)\right)=\varepsilon .
\end{aligned}
$$

Letting $k \rightarrow \infty$ in (17), by property of $\psi$ and (22), we get

$$
\psi(\varepsilon) \leq \psi(\varepsilon)-\phi(\varepsilon)<\psi(\varepsilon)
$$

which is a contradiction. Therefore, $\left\{c x_{n}\right\}_{n \in \mathbb{N}}$ is $\rho$-Cauchy. Since $X_{\rho}$ is $\rho$-complete there exists a point $u \in X_{\rho}$ such that $\rho\left(c\left(x_{n}-u\right)\right) \rightarrow 0$ as $n \rightarrow \infty$. Consequently, $\rho\left(l\left(x_{n}-u\right)\right) \rightarrow 0$ as $n \rightarrow \infty$. Next, we prove that $u$ is a unique fixed point of $T$. Putting $x=x_{n-1}$ and $y=u$ in (10), we obtain

$$
\begin{aligned}
\psi\left(\rho\left(c\left(x_{n}-T u\right)\right)\right) \leq & \psi\left(\rho\left(l\left(x_{n-1}-u\right)\right)\right) \\
& -\phi\left(\rho\left(l\left(x_{n-1}-u\right)\right)\right) .
\end{aligned}
$$

Taking $n \rightarrow \infty$ in the inequality (24), we have

$$
\psi(\rho(c(u-T u))) \leq \psi(0)-\phi(0)=0,
$$

which implies that $\rho(c(T u-u))=0$ and $T u=u$. Suppose that there exists $v \in X_{\rho}$ such that $T v=v$ and $v \neq u$, and then we have

$$
\begin{aligned}
\psi(\rho(c(u-v))) & =\psi(\rho(c(T u-T v))) \\
& \leq \psi(\rho(l(u-v)))-\phi(\rho(l(u-v))) \\
& <\psi(\rho(l(u-v))) \\
& \leq \psi(\rho(c(u-v)))
\end{aligned}
$$

which is a contradiction. Hence $u=v$ and the proof is complete.

Corollary 11. Let $X_{\rho}$ be a $\rho$-complete modular space, where $\rho$ satisfies the $\Delta_{2}$-condition. Let $c, l \in \mathbb{R}^{+}, c>l$, and $T: X_{\rho} \rightarrow$ $X_{\rho}$ be a mapping satisfying the inequality

$$
\begin{aligned}
\rho(c(T x-T y)) \leq & \rho(l(x-y)) \\
& -\phi(\rho(l(x-y))),
\end{aligned}
$$

for all $x, y \in X_{\rho}$, where $\phi:[0, \infty) \rightarrow[0, \infty)$ is continuous and monotone nondecreasing function with $\phi(t)=0$ if and only if $t=0$. Then, $T$ has a unique fixed point. 
Proof. Take $\psi(t)=t$, and then we obtain the Corollary 11 .

Theorem 12. Let $X_{\rho}$ be a $\rho$-complete modular space, where $\rho$ satisfies the $\Delta_{2}$-condittion and let $T: X_{\rho} \rightarrow X_{\rho}$ be a mapping satisfying the inequality

$$
\begin{aligned}
\psi(\rho((T x-T y))) \leq & \psi(m(x, y)) \\
& -\phi(m(x, y))
\end{aligned}
$$

for all $x, y \in X_{\rho}$, where

$$
\begin{aligned}
m(x, y)=\max & \{\rho(x-y), \rho(x-T x), \rho(y-T y), \\
& \left.\left(\rho\left(\frac{1}{2}(x-T y)\right)+\rho\left(\frac{1}{2}(y-T x)\right)\right)(2)^{-1}\right\}
\end{aligned}
$$

and $\psi, \phi:[0, \infty) \rightarrow[0, \infty)$ are both continuous and monotone nondecreasing functions with $\psi(t)=\phi(t)=0$ if and only if $t=0$. Then, $T$ has a unique fixed point.

Proof. First, we prove that the sequence $\left\{\rho\left(c\left(T^{n} x-T^{n-1} x\right)\right)\right\}$ converges to 0 . Since,

$$
\begin{aligned}
\psi\left(\rho\left(T^{n} x-T^{n-1} x\right)\right) \leq & \psi\left(m\left(T^{n-1} x, T^{n-2} x\right)\right) \\
& -\phi\left(m\left(T^{n-1} x, T^{n-2} x\right)\right) . \\
\leq & \psi\left(m\left(T^{n-1} x, T^{n-2} x\right)\right) .
\end{aligned}
$$

By monotone nondecreasing of $\psi$, we have

$$
\rho\left(T^{n} x-T^{n-1} x\right) \leq m\left(T^{n-1} x, T^{n-2} x\right)
$$

From the definition of $m(x, y)$, we get

$$
\begin{aligned}
& m\left(T^{n-1} x, T^{n-2} x\right) \\
& =\max \left\{\rho\left(T^{n-1} x-T^{n-2} x\right)\right. \\
& \left.\qquad \rho\left(T^{n} x-T^{n-1} x\right), \frac{\rho\left((1 / 2)\left(T^{n} x-T^{n-2} x\right)\right)}{2}\right\} \\
& =\max \left\{\rho\left(T^{n-1} x-T^{n-2} x\right), \rho\left(T^{n} x-T^{n-1} x\right),\right. \\
& =\max \left\{\rho\left(T^{n-1} x-T^{n-2} x\right), \rho\left(T^{n} x-T^{n-1} x\right)\right\} \cdot
\end{aligned}
$$

If $\rho\left(T^{n} x-T^{n-1} x\right)>\rho\left(T^{n-1} x-T^{n-2} x\right) \geq 0$, then $m\left(T^{n-1} x\right.$, $\left.T^{n-2} x\right)=\rho\left(T^{n} x-T^{n-1} x\right)$. Furthermore it is implied that

$$
\begin{aligned}
\psi\left(\rho\left(T^{n} x-T^{n-1} x\right)\right) \leq & \left(m\left(T^{n-1} x, T^{n-2} x\right)\right) \\
& -\phi\left(m\left(T^{n-1} x, T^{n-2} x\right)\right) \\
\leq & \psi\left(\rho\left(T^{n} x-T^{n-1} x\right)\right) \\
& -\phi\left(\rho\left(T^{n} x-T^{n-1} x\right)\right) \\
< & \psi\left(\rho\left(T^{n} x-T^{n-1} x\right)\right)
\end{aligned}
$$

which is a contradiction, and, hence,

$$
\begin{aligned}
\rho\left(T^{n} x-T^{n-1} x\right) & \leq m\left(T^{n-1} x-T^{n-2} x\right) \\
& =\rho\left(T^{n-1} x-T^{n-2} x\right) .
\end{aligned}
$$

So, we have that the sequence $\left\{\rho\left(T^{n} x-T^{n-1} x\right)\right\}$ is monotone decreasing and bounded below. Hence there exists $r \geq 0$ such that

$$
\lim _{n \rightarrow \infty} \rho\left(T^{n} x-T^{n-1} x\right)=r
$$

If $r>0$, taking $n \rightarrow \infty$ in the inequality (30), we get

$$
\begin{aligned}
\psi(r) & \leq \psi(r)-\phi(r) \\
& <\psi(r)
\end{aligned}
$$

which is a contradiction, and thus $r=0$. So, we have

$$
\lim _{n \rightarrow \infty} \rho\left(T^{n} x-T^{n-1} x\right)=0
$$

Next, we prove that the sequence $\left\{T^{n}(x)\right\}_{n \in \mathbb{N}}$ is $\rho$-Cauchy. Suppose $\left\{T^{n}(x)\right\}_{n \in \mathbb{N}}$ is not $\rho$-Cauchy, and there exist $\varepsilon>0$ and sequence of integers $\left\{m_{k}\right\},\left\{n_{k}\right\}$ with $\left\{m_{k}\right\}>\left\{n_{k}\right\} \geq k$ such that

$$
\rho\left(\left(T^{m_{k}} x-T^{n_{k}} x\right)\right) \geq \varepsilon, \quad \rho\left(2\left(T^{m_{k}-1} x-T^{n_{k}} x\right)\right)<\varepsilon .
$$

Since,

$$
\begin{aligned}
\psi\left(\rho\left(\left(T^{m_{k}} x-T^{n_{k}} x\right)\right)\right) \leq & \psi\left(m\left(T^{m_{k}-1} x, T^{n_{k}-1} x\right)\right) \\
& -\phi\left(m\left(T^{m_{k}-1} x, T^{n_{k}-1} x\right)\right) \\
\leq & \psi\left(m\left(T^{m_{k}-1} x, T^{n_{k}-1} x\right)\right)
\end{aligned}
$$

which implies that

$$
\rho\left(\left(T^{m_{k}} x-T^{n_{k}} x\right)\right) \leq m\left(T^{m_{k}-1} x, T^{n_{k}-1} x\right) .
$$


On the other hand,

$$
\begin{aligned}
& m\left(T^{m_{k}-1} x, T^{n_{k}-1} x\right) \\
& =\max \left\{\rho\left(T^{m_{k}-1} x-T^{n_{k}-1} x\right),\right. \\
& \rho\left(T^{m_{k}} x-T^{m_{k}-1} x\right), \\
& \rho\left(T^{n_{k}} x-T^{n_{k}-1} x\right), \\
& \left(\rho\left(\frac{1}{2}\left(T^{m_{k}} x-T^{n_{k}-1} x\right)\right)\right. \\
& \left.\left.+\rho\left(\frac{1}{2}\left(T^{m_{k}-1} x-T^{n_{k}} x\right)\right)\right)(2)^{-1}\right\}, \\
& \rho\left(\left(T^{m_{k}-1} x-T^{n_{k}-1} x\right)\right) \\
& =\rho\left(\left(T^{m_{k}-1} x-T^{n_{k}} x+T^{n_{k}} x-T^{n_{k}-1} x\right)\right) \\
& \leq \rho\left(2\left(T^{m_{k}-1} x-T^{n_{k}} x\right)\right) \\
& +\rho\left(2\left(T^{n_{k}} x-T^{n_{k}-1} x\right)\right) \\
& <\varepsilon+\rho\left(2\left(T^{n_{k}} x-T^{n_{k}-1} x\right)\right) .
\end{aligned}
$$

For the last term in $m\left(T^{m_{k}-1} x, T^{n_{k}-1} x\right)$, by Proposition 8 , we have

$$
\begin{aligned}
\left(\rho\left(\frac{1}{2}\left(T^{m_{k}} x-T^{n_{k}-1} x\right)\right)+\rho\left(\frac{1}{2}\left(T^{m_{k}-1} x-T^{n_{k}} x\right)\right)\right)(2)^{-1} \\
=\left(\rho\left(\frac{1}{2}\left(T^{m_{k}-1} x-T^{n_{k}} x\right)\right)\right. \\
+\rho\left(\frac{1}{2}\left(T^{m_{k}} x-T^{m_{k}-1} x+T^{m_{k}-1} x-T^{n_{k}} x\right)\right. \\
\left.\left.\quad+\frac{1}{2}\left(T^{n_{k}} x-T^{n_{k}-1} x\right)\right)\right)(2)^{-1} \\
\leq\left(\rho\left(\frac{1}{2}\left(T^{m_{k}-1} x-T^{n_{k}} x\right)\right)\right. \\
\quad+\rho\left(T^{m_{k}} x-T^{m_{k}-1} x+T^{m_{k}-1} x-T^{n_{k}} x\right) \\
\left.\quad+\rho\left(T^{n_{k}} x-T^{n_{k}-1} x\right)\right)(2)^{-1} \\
\leq\left(\rho\left(\frac{1}{2}\left(T^{m_{k}-1} x-T^{n_{k}} x\right)\right)+\rho\left(2\left(T^{m_{k}} x-T^{m_{k}-1} x\right)\right)\right. \\
\left.\quad+\rho\left(2\left(T^{m_{k}-1} x-T^{n_{k}} x\right)\right)+\rho\left(T^{n_{k}} x-T^{n_{k}-1} x\right)\right)(2)^{-1} \\
<\varepsilon+\frac{\rho\left(T^{n_{k}} x-T^{n_{k}-1} x\right)+\rho\left(2\left(T^{m_{k}} x-T^{m_{k}-1} x\right)\right.}{2} .
\end{aligned}
$$

It follow from (41) and (42) that

$$
\begin{aligned}
& m\left(T^{m_{k}-1} x, T^{n_{k}-1} x\right) \\
& =\max \left\{\rho\left(T^{m_{k}-1} x-T^{n_{k}-1} x\right),\right. \\
& \rho\left(T^{m_{k}} x-T^{m_{k}-1} x\right), \rho\left(T^{n_{k}} x-T^{n_{k}-1} x\right), \\
& \left(\rho\left(\frac{1}{2}\left(T^{m_{k}} x-T^{n_{k}-1} x\right)\right)\right. \\
& \left.\left.+\rho\left(\frac{1}{2}\left(T^{m_{k}-1} x-T^{n_{k}} x\right)\right)\right)(2)^{-1}\right\} \\
& <\max \left\{\varepsilon+\rho\left(2\left(T^{n_{k}} x-T^{n_{k}-1} x\right)\right),\right. \\
& \rho\left(T^{m_{k}} x-T^{m_{k}-1} x\right), \rho\left(T^{n_{k}} x-T^{n_{k}-1} x\right), \varepsilon \\
& \left.+\frac{\rho\left(T^{n_{k}} x-T^{n_{k}-1} x\right)+\rho\left(2\left(T^{m_{k}} x-T^{m_{k}-1} x\right)\right.}{2}\right\} \text {. }
\end{aligned}
$$

By (37), (38), (40), (43), and the $\Delta_{2}$-condition of $\rho$, we have

$$
\lim _{k \rightarrow \infty} \rho\left(\left(T^{m_{k}} x-T^{n_{k}} x\right)\right)=\lim _{k \rightarrow \infty} m\left(T^{m_{k}-1} x, T^{n_{k}-1} x\right)=\varepsilon .
$$

Taking $k \rightarrow \infty$ in (39), by (44) and the continuity of $\psi$, we get

$$
\psi(\varepsilon) \leq \psi(\varepsilon)-\phi(\varepsilon)<\psi(\varepsilon)
$$

which is a contradiction. Hence, $\left\{T^{n}(x)\right\}_{n \in \mathbb{N}}$ is $\rho$-Cauchy. Since $X_{\rho}$ is $\rho$-complete, there exists a point $u \in X_{\rho}$ such that $\rho\left(T^{n} x-u\right) \rightarrow 0$ as $n \rightarrow \infty$. Next, we prove that $u$ is a unique fixed point of $T$. Suppose that $T u \neq u$, then $\rho(u-T u)>0$.

Since,

$$
\begin{gathered}
\psi\left(\rho\left(T^{n} x-T u\right)\right) \leq \psi\left(m\left(T^{n-1} x, u\right)\right) \\
-\phi\left(m\left(T^{n-1} x, u\right)\right), \\
m\left(T^{n-1} x, u\right) \\
=\max \left\{\rho\left(T^{n-1} x-u\right), \rho\left(T^{n-1} x-T^{n} x\right),\right. \\
\rho(u-T u),\left(\rho\left(\frac{1}{2}\left(T^{n-1} x-T u\right)\right)\right. \\
\left.\left.+\rho\left(\frac{1}{2}\left(u-T^{n} x\right)\right)\right)(2)^{-1}\right\} \\
\longrightarrow \max \left\{0,0, \rho(u-T u), \frac{\rho((1 / 2)(u-T u))}{2}\right\} \\
=\rho(u-T u)
\end{gathered}
$$


Taking $n \rightarrow \infty$ in (46), by using (47), we get

$$
\begin{aligned}
\psi(\rho(u-T u)) & \leq \psi(\rho(u-T u))-\phi(\rho(u-T u)) \\
& <\psi(\rho(u-T u))
\end{aligned}
$$

which is a contradiction. Hence, $\rho(u-T u)=0$ and $T u=u$. If there exists point $v \in X_{\rho}$ such that $T v=v$ and $u \neq v$, then using an argument similar to the above we get

$$
\begin{aligned}
\psi(\rho(u-v)) & =\psi(\rho(T u-T v)) \\
& \leq \psi(m(u, v))-\phi(m(u, v)) \\
& \leq \psi(\rho(u-v))-\phi(\rho(u-v)) \\
& <\psi(\rho(u-v))
\end{aligned}
$$

which is a contradiction. Hence, $u=v$ and the proof is complete.

Corollary 13. Let $X_{\rho}$ be a $\rho$-complete modular space, where $\rho$ satisfies the $\Delta_{2}$-condition, and let $T: X_{\rho} \rightarrow X_{\rho}$ be a mapping satisfying the inequality

$$
\rho((T x-T y)) \leq m(x, y)-\phi(m(x, y))
$$

for all $x, y \in X_{\rho}$, where $m(x, y)=\max \{\rho(x-y), \rho(x-T x)$, $\rho(y-T y),(\rho((1 / 2)(x-T y))+\rho((1 / 2)(y-T x))) / 2\}$ and $\phi:$ $[0, \infty) \rightarrow[0, \infty)$ is continuous and monotone nondecreasing function with $\phi(t)=0$ if and only ift $=0$. Then, $T$ has a unique fixed point.

Proof. Taking $\psi(t)=t$, we obtain the Corollary 13 .

\section{Acknowledgments}

This work was supported by the Higher Education Research Promotion and National Research University Project of Thailand, Office of the Higher Education Commission. The authors would like to thank the referee for his comments and suggestion. C. Mongkolkeha was supported from the Thailand Research Fund through the the Royal Golden Jubilee Ph.D. Program (Grant no. PHD/0029/2553).

\section{References}

[1] Ya. I. Alber and S. Guerre-Delabriere, "Principle of weakly contractive maps in Hilbert spaces," in New Results in Operator Theory and Its Applications, I. Gohberg and Yu. Lyubich, Eds., vol. 98 of Operator Theory: Advances and Applications, pp. 7-22, Birkhäuser, Basel, Switzerland, 1997.

[2] B. E. Rhoades, "Some theorems on weakly contractive maps," in Proceedings of the 3rd World Congress of Nonlinear Analysts, Part 4 (Catania, 2000), vol. 47, pp. 2683-2693, 2001.

[3] P. N. Dutta and B. S. Choudhury, "A generalisation of contraction principle in metric spaces," Fixed Point Theory and Applications, vol. 2008, Article ID 406368, 8 pages, 2008.

[4] H. Nakano, Modulared Semi-Ordered Linear Spaces, vol. 1 of Tokyo Mathematical Book Series, Maruzen, Tokyo, Japan, 1950.

[5] H. Nakano, Topology of Linear Topological Spaces, vol. 3 of Tokyo Mathematical Book Series, Maruzen, Tokyo, Japan, 1951.
[6] J. Musielak and W. Orlicz, “On modular spaces," Studia Mathematica, vol. 18, pp. 49-65, 1959.

[7] W. A. J. Luxemburg, Banach function spaces [Ph.D. thesis], Delft Institute of Technology, Assen, The Netherlands, 1955.

[8] S. Mazur and W. Orlicz, "On some classes of linear spaces," Studia Mathematica, vol. 17, pp. 97-119, 1958.

[9] Ph. Turpin, "Fubini inequalities and bounded multiplier property in generalized modular spaces," Commentationes Mathematicae, vol. 1, pp. 331-353, 1978.

[10] R. A. Adams, Sobolev Spaces, vol. 65 of Pure and Applied Mathematics, Academic Press, New York, NY, USA, 1975.

[11] L. Maligranda, Orlicz Spaces and Interpolation, vol. 5 of Seminars in Mathematics, Universidade Estadual de Campinas, Departamento de Matemática, Campinas, Brazil, 1989.

[12] J. Musielak, Orlicz Spaces and Modular Spaces, vol. 1034 of Lecture Notes in Mathematics, Springer, Berlin, Germany, 1983.

[13] S. Rolewicz, Metric Linear Spaces, PWN-Polish Scientific Publishers, Warsaw, Poland, 2nd edition, 1984.

[14] M. M. Rao and Z. D. Ren, Applications of Orlicz Spaces, vol. 250 of Monographs and Textbooks in Pure and Applied Mathematics, Marcel Dekker, New York, NY, USA, 2002.

[15] M. A. Khamsi, W. M. Kozłowski, and S. Reich, "Fixed point theory in modular function spaces," Nonlinear Analysis. Theory, Methods \& Applications, vol. 14, no. 11, pp. 935-953, 1990.

[16] M. A. Khamsi, "Fixed point theory in modular function spaces," in Recent Advances on Metric Fixed Point Theory (Seville, 1995), vol. 48 of Ciencias, pp. 31-57, Universidad de Sevilla, Seville, Spain, 1996.

[17] M. Beygmohammadi and A. Razani, "Two fixed-point theorems for mappings satisfying a general contractive condition of integral type in the modular space," International Journal of Mathematics and Mathematical Sciences, vol. 2010, Article ID 317107, 10 pages, 2010.

[18] C. Mongkolkeha and P. Kumam, "Fixed point and common fixed point theorems for generalized weak contraction mappings of integral type in modular spaces," International Journal of Mathematics and Mathematical Sciences, vol. 2011, Article ID 705943, 12 pages, 2011.

[19] T. Dominguez Benavides, M. A. Khamsi, and S. Samadi, "Uniformly Lipschitzian mappings in modular function spaces," Nonlinear Analysis. Theory, Methods \& Applications, vol. 46, no. 2, pp. 267-278, 2001.

[20] M. A. Khamsi, "Uniform noncompact convexity, fixed point property in modular spaces," Mathematica Japonica, vol. 40, no. 3, pp. 439-450, 1994.

[21] M. A. Khamsi, "Quasicontraction mappings in modular spaces without $\Delta_{2}$-condition," Fixed Point Theory and Applications, vol. 2008, Article ID 916187, 6 pages, 2008.

[22] P. Kumam, "Fixed point theorems for nonexpansive mappings in modular spaces," Archivum Mathematicum, vol. 40, no. 4, pp. 345-353, 2004

[23] K. Kuaket and P. Kumam, "Fixed points of asymptotic pointwise contractions in modular spaces," Applied Mathematics Letters, vol. 24, no. 11, pp. 1795-1798, 2011.

[24] A. Razani and R. Moradi, "Common fixed point theorems of integral type in modular spaces," Bulletin of the Iranian Mathematical Society, vol. 35, no. 2, pp. 11-24, 2009. 


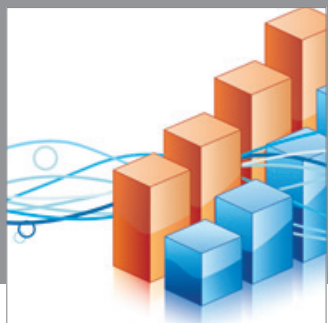

Advances in

Operations Research

mansans

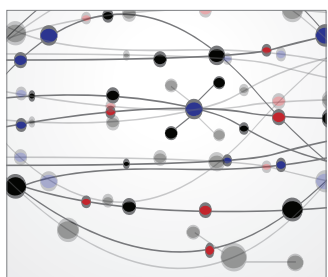

The Scientific World Journal
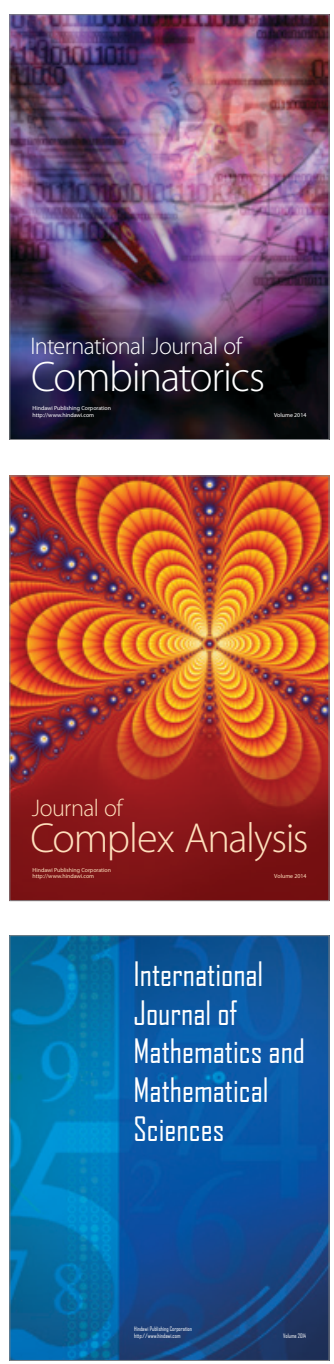
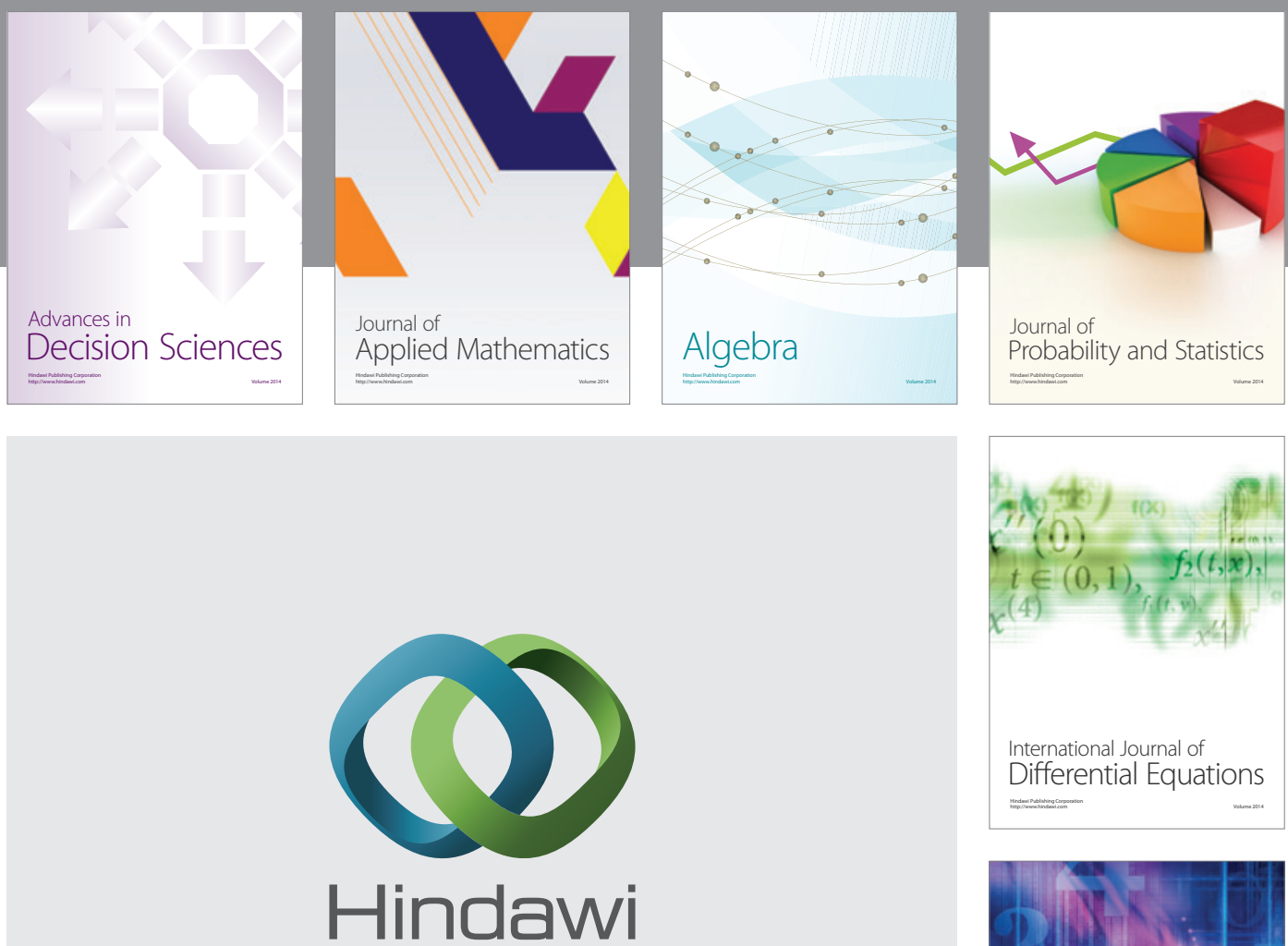

Submit your manuscripts at http://www.hindawi.com
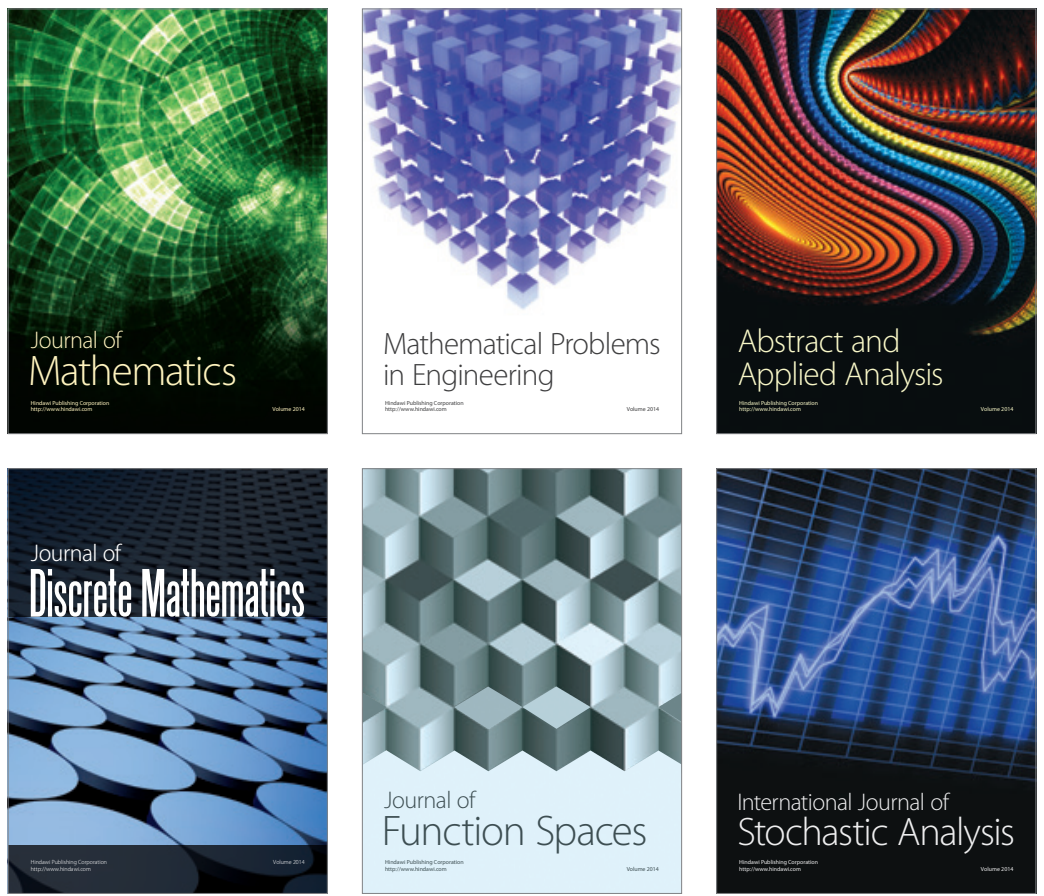

Journal of

Function Spaces

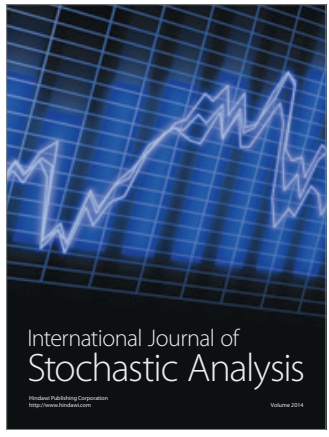

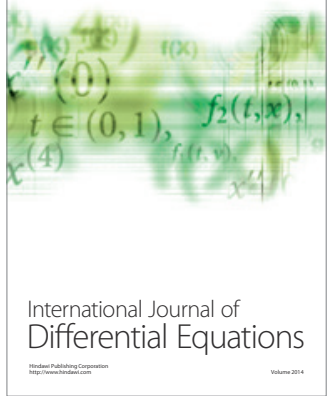
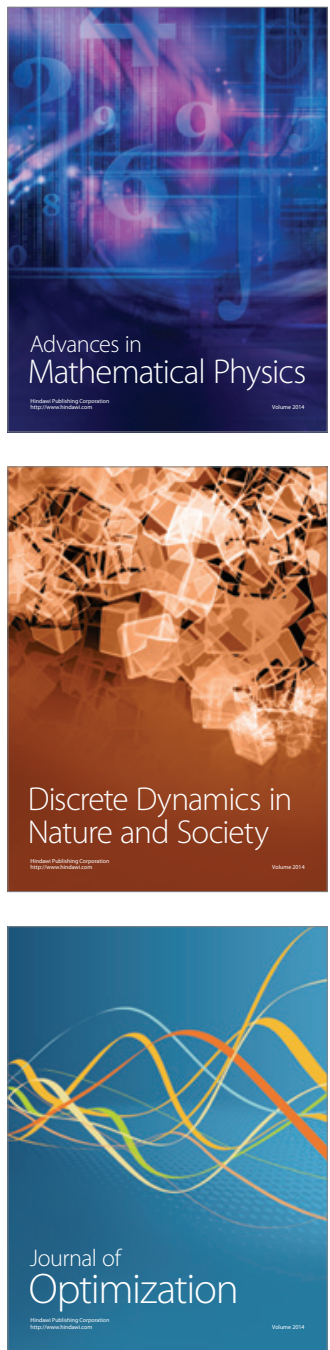